\title{
Imóveis invadidos pela água oriundos de chuvas extremas na Região Metropolitana de Campinas (SP)
}

\author{
Marina Sória Castellano ${ }^{(a)}$, Lucí Hidalgo Nunes ${ }^{(b)}$ \\ (a) Centro de Ciências Humanas, Universidade Estadual do Oeste do Paraná, nina_soria@ yahoo.com.br \\ (b) Departamento de Geografia, Universidade Estadual de Campinas, luci@ige.unicamp.br
}

\section{Eixo: Climatologia em diferentes níveis escalares: mudanças e variabilidades}

\begin{abstract}
Resumo
O objetivo foi levantar ocorrências de imóveis invadidos pela água ocasionadas por chuvas extremas na Região Metropolitana de Campinas entre 1970 e 2009, identificando onde ocorreram com mais frequência e quais os grupos sociais afetados. Os extremos foram identificados pela técnica dos quantis, o levantamento dos impactos em jornais e órgãos oficiais e o mapeamento das ocorrências, com base no Atlas da Vulnerabilidade Social do IPEA. Grande parte das ocorrências se deu em áreas de baixa ou muito baixa vulnerabilidade, fato que pode estar ligado à diminuição da desigualdade no Brasil na última década. Porém, alguns bairros bastante atingidos referem-se a áreas de mais alta vulnerabilidade. Assim, toda a população está exposta ao risco, independente da classe social. Campinas se destacou por ter tido mais ocorrências, porém, houve melhora entre os períodos, mostrando que as ações da Defesa Civil podem estar surtindo efeito no sentido de amenizar os impactos.
\end{abstract}

Palavras chave: Chuvas extremas, impactos, Região Metropolitana de Campinas

\section{Introdução e objetivo}

Em ambientes alterados pela ação humana, episódios extremos - aqueles que se desviam dos registros mais constantes e ultrapassam um limiar habitual de dado fenômeno (NUNES, 2009) - , tem alto potencial em causar prejuízos significativos em cidades de todo o mundo.

A maneira como o evento natural irá afetar grupos sociais de formas distintas depende da vulnerabilidade, que está intimamente relacionada a uma série de processos de ordem social, econômico, cultural e político (BRAGA et al., 2006). Normalmente, a noção de vulnerabilidade surge associada com as condições socioeconômicas da população envolvida, embora tal explicação seja simplista para elucidar a ocorrência de todos os desastres (WISNER et al., 1994).

Como em muitos outros locais, a Região Metropolitana de Campinas (RMC - Figura 1) tem sido palco de uma série de impactos associados às chuvas, que acarretam diversos problemas socioambientais, principalmente em meio urbano. Assim, o objetivo foi levantar as ocorrências de imóveis invadidos pela água ocasionadas por chuvas extremas nos municípios da RMC em 40 anos, identificando onde os casos ocorreram com mais frequência e quais os estratos sociais mais afetados. 
A RMC é formada por 20 municípios: Americana, Artur Nogueira, Campinas, Cosmópolis, Engenheiro Coelho, Holambra, Hortolândia, Indaiatuba, Itatiba, Jaguariúna, Monte Mor, Morungaba ${ }^{1}$, Nova Odessa, Paulínia, Pedreira, Santa Bárbara d'Oeste, Santo Antonio de Posse, Sumaré, Valinhos e Vinhedo.
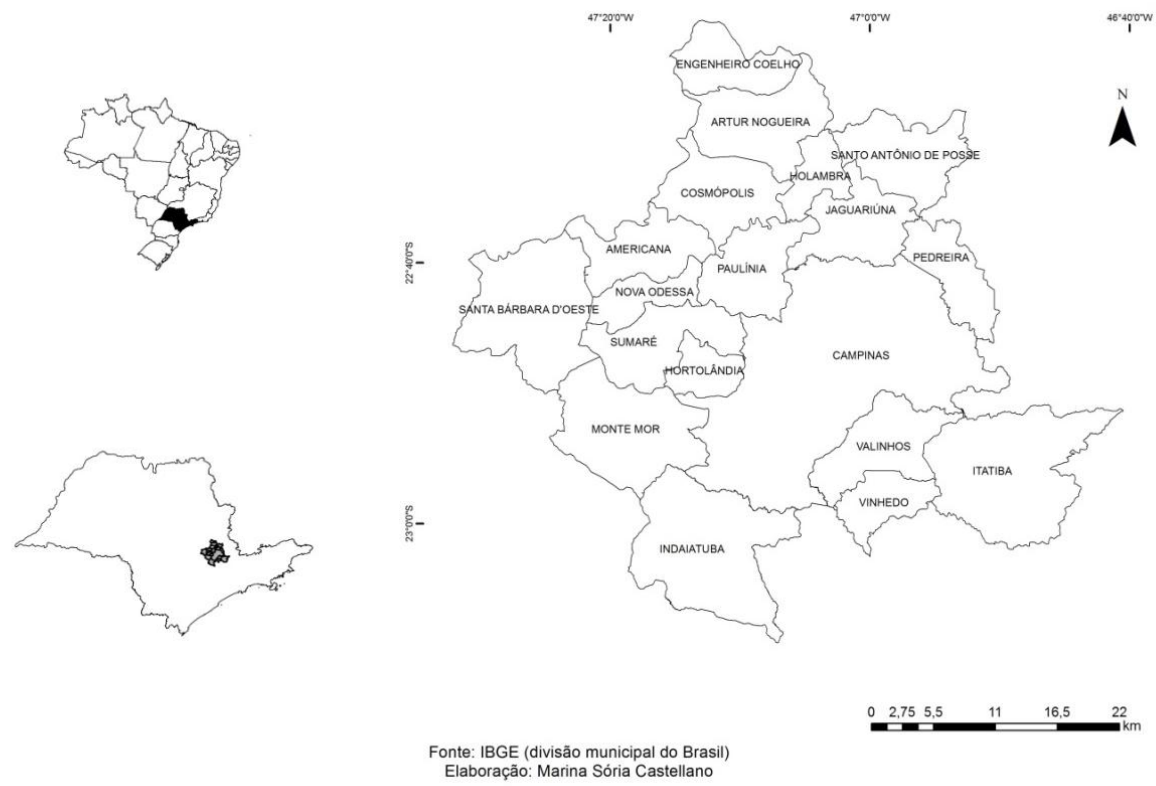

Figura 1: Localização da Região Metropolitana de Campinas

A Região tem atualmente cerca de 2,9 milhões de habitantes (SEADE, 2015) e destaca-se por sua diversificação econômica, incluindo atividades terciárias, industriais e agropecuárias (FERNANDES et al, op. cit), além de ser reconhecido pólo de ciência e alta tecnologia. Apesar de deter grande parte da renda nacional, é caracterizada pelo alto grau de desigualdade e segregação socioespacial, com falta de infraestrutura à algumas parcelas da população, expansão desordenada da mancha urbana (PIRES e SANTOS, 2002).

\section{Metodologia}

Foram utilizados dados diários de precipitação de 11 postos pluviométricos do Departamento de Água e Energia Elétrica do Estado de São Paulo e do Instituto Agronômico de Campinas, entre 1970 e 2009.

Os dias em que ocorreram eventos extremos foram identificados pela técnica dos quantis, utilizada para a definição de classes de excepcionalidade de acordo com a característica da precipitação dos municípios. Um quantil de ordem $\mathrm{p}$ (definido para $0<\mathrm{p}<1$ ) é um valor numérico que secciona a distribuição em duas

\footnotetext{
${ }^{1}$ Morungaba não foi contemplado nesse estudo, pois passou a fazer parte da RMC em abril de 2014 e não haveria tempo hábil para a inclusão do município uma vez que a pesquisa já estava em andamento.
} 
partes, com probabilidades $\mathrm{p}$ à esquerda desse quantil teórico, e 1-p à direita, onde os valores acima e abaixo do estabelecido por um dado quantil perfazem 100,0\%. Foram definidos como faixa de probabilidade os dias em que ocorreram precipitações acima de $95,0 \%$, com exceção dos meses menos chuvosos (maio, junho, julho e agosto), quando se levou em consideração os dias acima de 97,5\%.

O levantamento dos impactos para todos os municípios foi feito em arquivos públicos municipais, bibliotecas, Defesas Civis, Corpo de Bombeiros, Guardas Municipais, museus e jornais.

O mapeamento das ocorrências ${ }^{2}$ foi baseado no Atlas da Vulnerabilidade Social do Instituto de Pesquisa Econômica Aplicada (IPEA), onde se teve acesso ao Índice de Vulnerabilidade Social (IVS), composto por indicadores relacionados ao saneamento básico, saúde, educação e renda. Tais dados baseiam-se nos Censos Demográficos do IBGE de 2000 e 2010 e foram normalizados numa escala de 0 a 1 , onde o 0 corresponde à situação de menor vulnerabilidade e o 1, à maior vulnerabilidade, dando origem ao IVS.

Com o intuito de conhecer aspectos da realidade socioeconômica no nível intramunicipal, foram utilizados dados do IVS para porções menores, denominadas de UDH (Unidades de Desenvolvimento Humano), referentes a áreas com características sociais e econômicas homogêneas.

Dois tipos de mapas foram confeccionados: no primeiro, constam os valores absolutos das ocorrências para cada UDH, nas duas décadas; no segundo, é possível perceber quais UDHs mostraram aumento ou diminuição nos casos entre 1990 e 2000. Para tanto, foi utilizado o Índice de Mudança $\left(I_{M}\right)$, considerandose, como período antigo $\left(\mathrm{V}_{\mathrm{PA}}\right)$ a década de 1990 e, como período novo $\left(\mathrm{V}_{\mathrm{PN}}\right)$, a de 2000:

$$
\mathrm{I}_{\mathrm{M}}=\left[\left(\mathrm{V}_{\mathrm{PA}}-\mathrm{V}_{\mathrm{PN}}\right) / \mathrm{V}_{\mathrm{PA}}\right] \times 100
$$

\section{Resultados}

Os números absolutos de imóveis invadidos pela água são mostrados na Tabela I, divididos por municípios, para os 40 anos considerados:

${ }^{2}$ Foram desconsiderados os municípios de Engenheiro Coelho, Santo Antonio de Posse e Holambra, devido à ausência de setores censitários no Censo de 2000. 
Tabela I: Imóveis invadidos pela água (números absolutos) por municípios (1970 a 2009)

\begin{tabular}{|c|c|}
\hline Municípios & $\mathrm{N}^{0}$ de imóveis invadidos pela água \\
\hline Campinas & 4.733 \\
\hline Sumaré & 979 \\
\hline Santa Bárbara d’Oeste & 479 \\
\hline Americana & 417 \\
\hline Itatiba & 232 \\
\hline Hortolândia & 224 \\
\hline Indaiatuba & 197 \\
\hline Nova Odessa & 135 \\
\hline Valinhos & 133 \\
\hline Cosmópolis & 75 \\
\hline Jaguariúna & 75 \\
\hline Vinhedo & 54 \\
\hline Pedreira & 51 \\
\hline Paulínia & 48 \\
\hline Monte Mor & 15 \\
\hline Artur Nogueira & 4 \\
\hline Total & $\mathbf{7 . 8 5 1}$ \\
\hline
\end{tabular}

Elaboração: Marina Sória Castellano

Campinas se destaca, uma vez que teve mais ocorrências do que todos os outros municípios juntos. Tal fato se atrela ao exposto por Hogan et al. (2001), que afirmaram que Campinas tem um sistema de drenagem bastante antigo e, portanto, inadequado para os dias atuais, que, junto à alta impermeabilização e eliminação de áreas verdes, contribuem para que se acentuem os problemas relacionados com às chuvas. No município, a área conhecida como Residencial Gênesis (Jardim São Quirino), se destacou com muitas ocorrências. Trata-se de ocupação irregular à beira do ribeirão Anhumas e que correspondia, em 1990, a UDH com muito alta vulnerabilidade (IVS de 0,53, um dos mais altos índices para Campinas), e que passa a ser considerada de média vulnerabilidade em 2000 (IVS de 0,36).

Em 2008 foram iniciadas intervenções de recuperação da mata ciliar e remoção e reassentamento de famílias, que foram realocadas em 210 imóveis. As obras fizeram parte do Programa de Aceleração do Crescimento (PAC) do Governo Federal em parceria com a Prefeitura. Em trabalho de campo, notou-se que algumas dessas unidades foram construídas no mesmo local onde estavam os antigos imóveis, porém com aumento da cota em até 5 metros acima do nível 


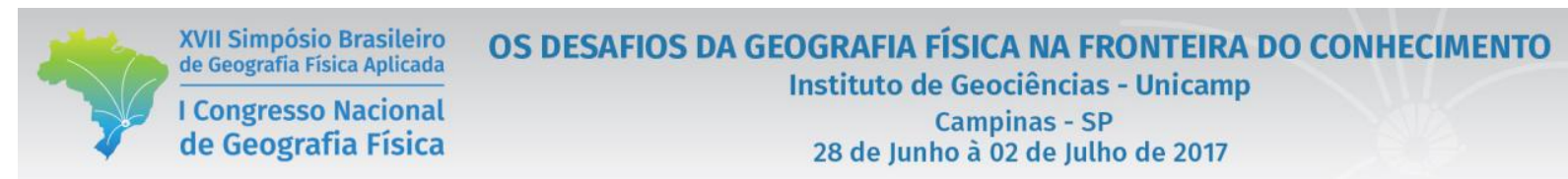

original $^{3}$. As áreas são mostradas na Figura 2, em dois períodos: em 2002, com a ocupação de imóveis precários; e em 2016, com a presença de imóveis provenientes do PAC.

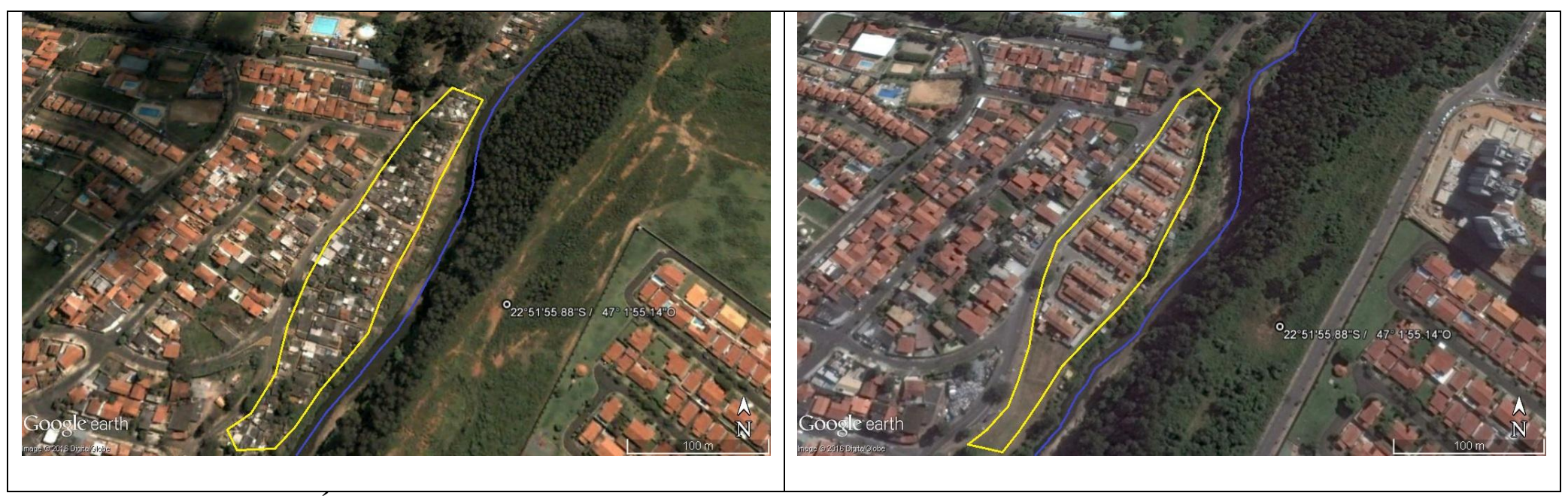

Figura 2: a) Área de risco ocupada (em destaque) no Residencial Gênesis, em Campinas. Data: 04/05/2002. Fonte: Google Earth. b) Área de risco desocupada por habitações irregulares e ocupada por moradias de programas sociais (em destaque) no Residencial Gênesis, em Campinas. Data: 05/04/2016. Fonte: Google Earth

Segundo a Defesa Civil de Campinas, atualmente a área não é mais considerada de risco, uma vez que grande parte dos habitantes foi retirada. Porém, foi questionado o método de reassentamento da população exatamente no mesmo lugar onde antes eram registradas as ocorrências e o órgão disse não saber do fato. Causa estranheza a ocupação das mesmas áreas onde antes existiam habitações precárias por imóveis de programas habitacionais, uma vez que estas continuam localizadas em área de risco, ainda que as cotas tenham sido alteradas.

As ocorrências para cada UDH são apresentadas na Figura 3, para as décadas de 1990 e 2000:

\footnotetext{
${ }^{3}$ Informação dada pelo arquiteto da Construtora Encalso, responsável pela obra, em visita feita ao local em 12 de julho de 2010.
} 
XVII Simpósio Brasileiro de Geografia Física Aplicada

I Congresso Nacional de Geografia Fisica
OS DESAFIOS DA GEOGRAFIA FÍSICA NA FRONTEIRA DO CONHECIMENTO

Instituto de Geociências - Unicamp

Campinas - SP

28 de Junho à 02 de Julho de 2017

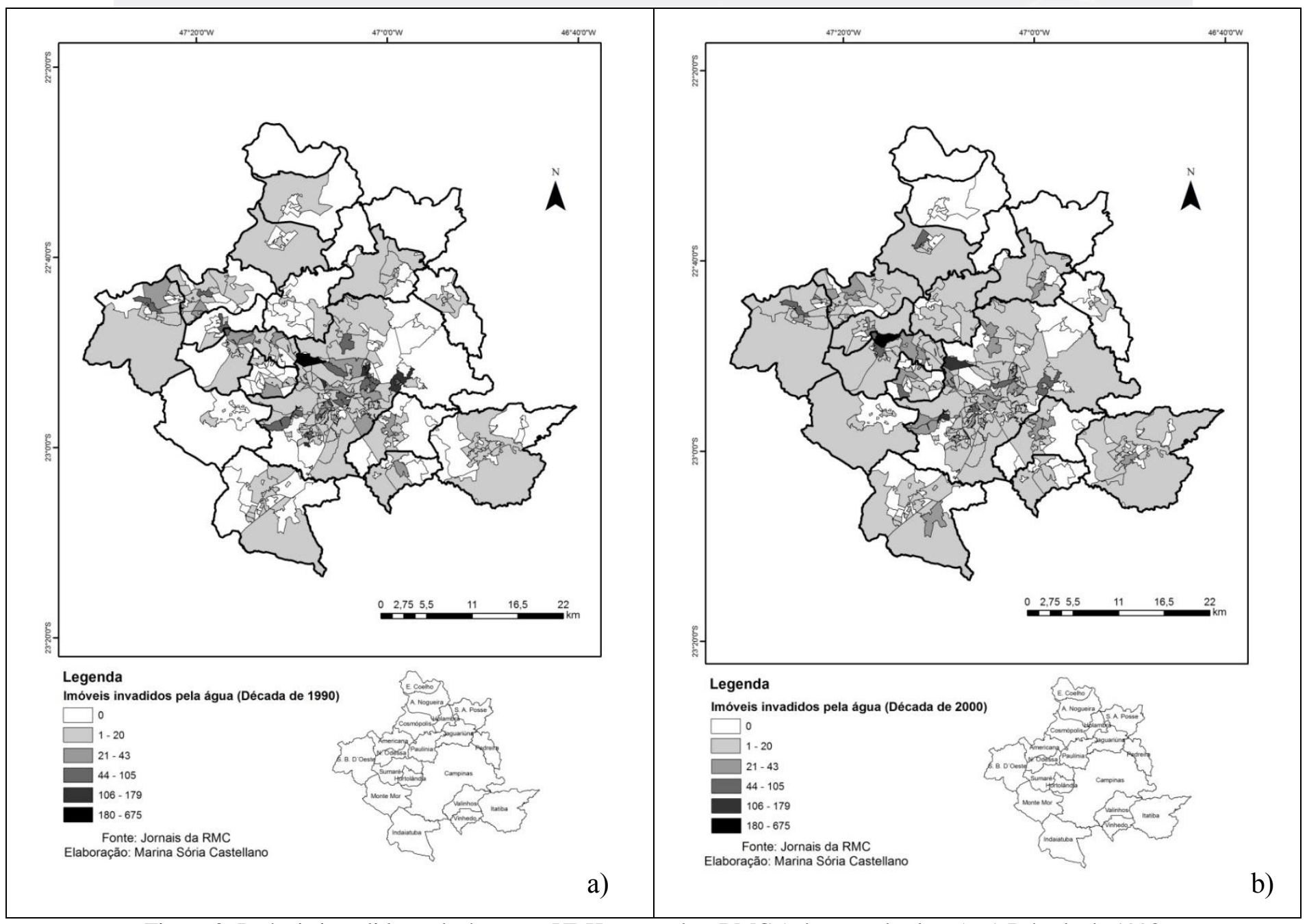

Figura 3: Imóveis invadidos pela água por UDH para toda a RMC (números absolutos). a) Década de 1990 (representada pelo censo de 2000); b) Década de 2000 (representada pelo censo de 2010)

$\mathrm{Na}$ década de 1990, os municípios que se destacaram por apresentarem UDHs com muitos casos foram Americana, Campinas, Santa Bárbara d'Oeste e Sumaré. Campinas se sobressaiu nesse decênio por apresentar as UDHs com mais ocorrências. Já nos anos 2000, a tendência se altera levemente: Campinas e Sumaré continuam a apresentar muitos casos, porém Hortolândia e Santa Bárbara d'Oeste se destacam.

A análise baseada na vulnerabilidade da população para cada município e década é mostrada a seguir, na Figura 4: 
XVII Simpósio Brasileiro de Geografia Fisica Aplicada

I Congresso Nacional de Geografia Fisica
OS DESAFIOS DA GEOGRAFIA FÍSICA NA FRONTEIRA DO CONHECIMENTO

Instituto de Geociências - Unicamp

Campinas - SP

28 de Junho à 02 de Julho de 2017

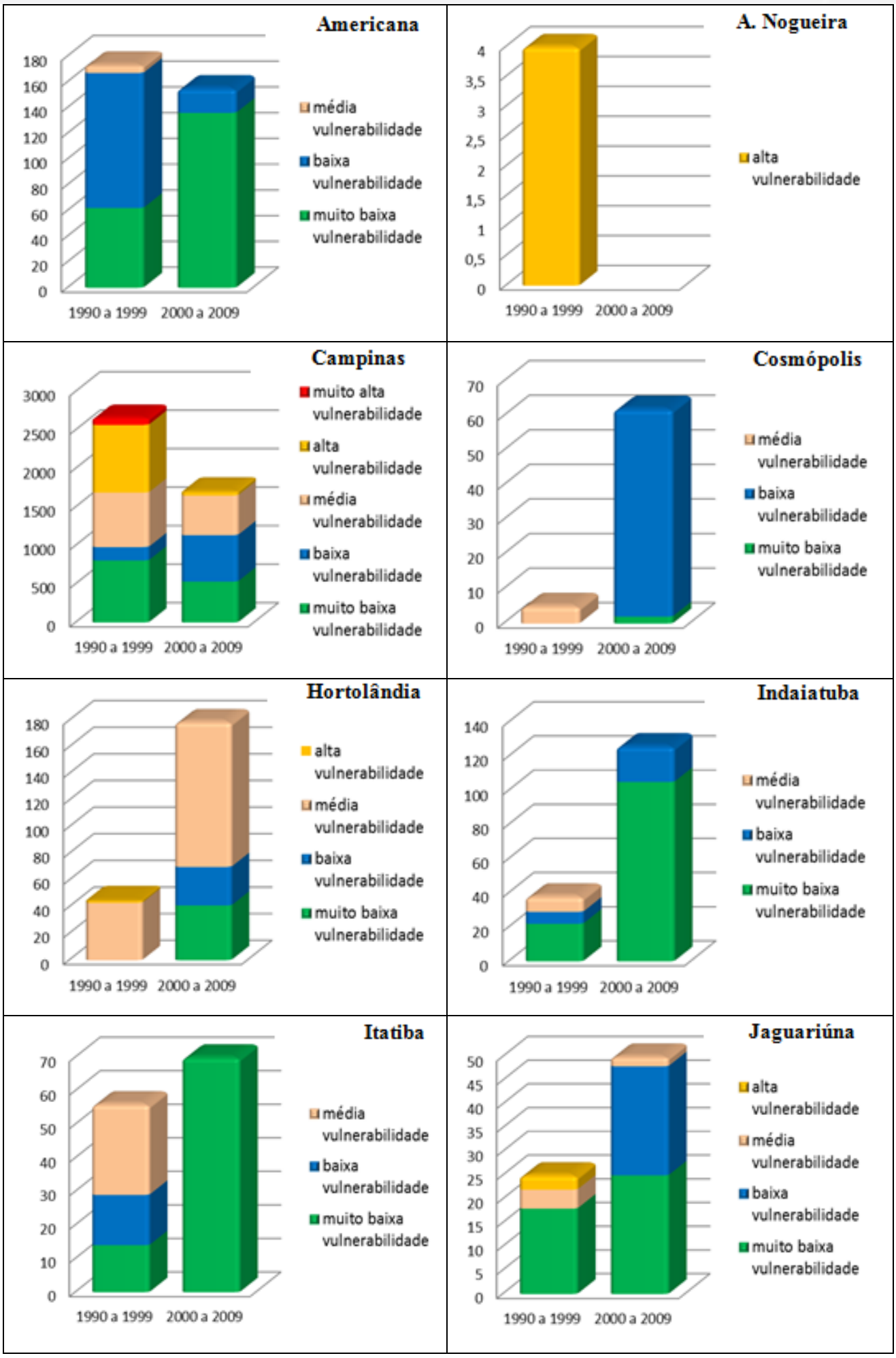


XVII Simpósio Brasileiro de Geografia Física Aplicada

I Congresso Nacional de Geografia Física
OS DESAFIOS DA GEOGRAFIA FÍSICA NA FRONTEIRA DO CONHECIMENTO

Instituto de Geociências - Unicamp

Campinas - SP

28 de Junho à 02 de Julho de 2017

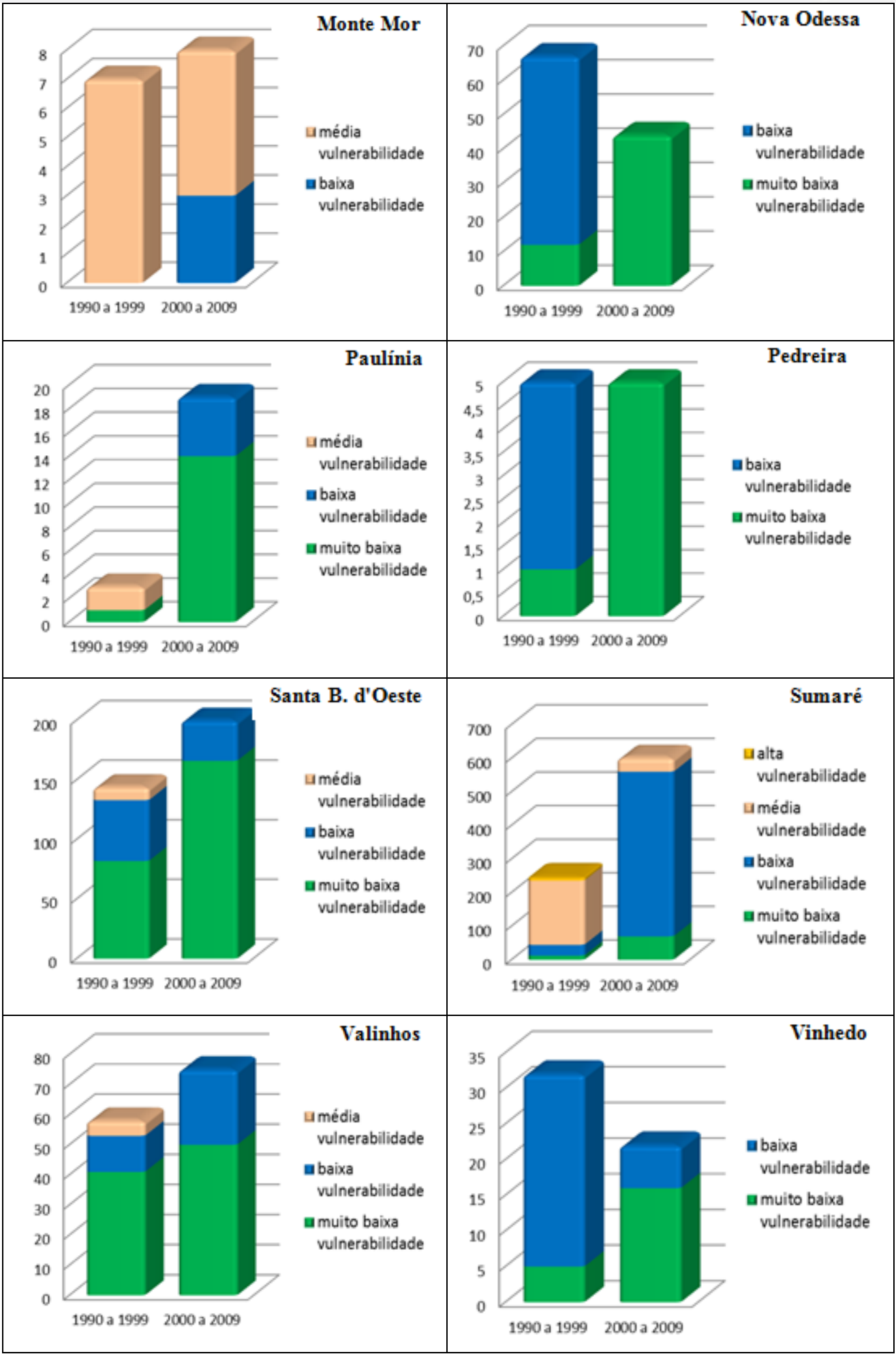

Figura 4: Imóveis invadidos pela água por municípios e faixas de vulnerabilidade (décadas de 1990 e 2000). Elaboração: Marina Sória Castellano

Dez municípios apresentaram aumento de 1990 para 2000: Cosmópolis, Hortolândia, Indaiatuba, Itatiba, Jaguariúna, Monte Mor, Paulínia, Santa Bárbara d'Oeste, Sumaré e Valinhos. 
Grande parte dos eventos se deu em áreas de baixa e muito baixa vulnerabilidade, nos dois períodos.

Porém, alguns municípios se destacaram por apresentarem imóveis invadidos pela água em áreas de alta vulnerabilidade: Artur Nogueira, Campinas, Hortolândia, Jaguariúna e Sumaré. Todos eles, com exceção de Campinas, tiveram casos nessas áreas apenas na década de 1990, apresentando melhora no decênio mais recente. Campinas também se destacou negativamente por apresentar ocorrências em áreas de muito alta vulnerabilidade, ainda que apenas no primeiro período.

Os dados para todos os municípios, por faixa de vulnerabilidade, podem ser vistos na Figura 5:

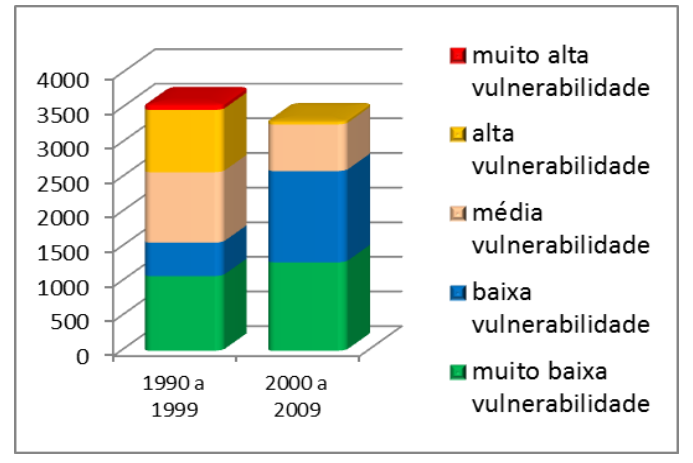

Figura 5: Imóveis invadidos pela água em todos os municípios, por faixas de vulnerabilidade (décadas de 1990 e 2000). Elaboração: Marina Sória Castellano

$\mathrm{Na}$ análise geral, houve melhora da década de 1990 para a de 2000. Além da diminuição nos casos com o passar do tempo, percebe-se que, na segunda década, as ocorrências se deram, em sua maioria, em áreas de muito baixa e baixa vulnerabilidade, mostrando que a população mais vulnerável foi menos atingida.

A comparação entre os decênios de acordo com o índice de mudança é mostrada na Figura 6: 


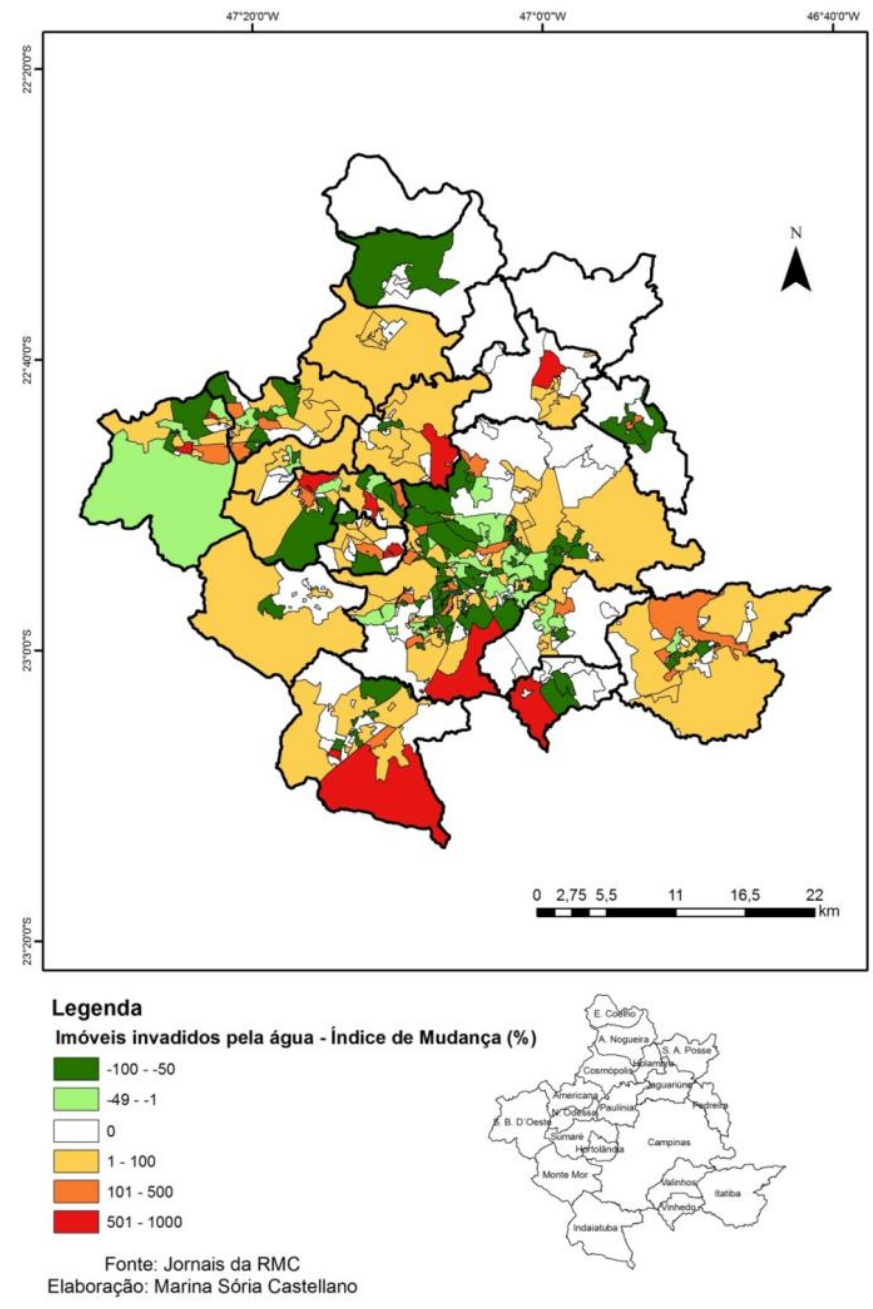

Figura 6: Imóveis invadidos pela água por UDH para toda a RMC de acordo com o Índice de Mudança (décadas de 1990 e 2000)

Destacam-se Americana, Cosmópolis, Jaguariúna e Santa Bárbara d'Oeste, todos com mais de 40,0\% de UDHs com aumento. Cosmópolis e Jaguariúna foram as únicas cidades sem nenhuma UDH com diminuição e Artur Nogueira não teve UDHs com aumento.

Indaiatuba se sobressaiu em âmbito regional como o município que apresentou uma das UDHs com maior porcentagem de aumento de uma década para a outra. Trata-se de área onde está o bairro Jardim Oliveira Camargo (Figura 7), área com um dos mais altos índices de vulnerabilidade do município em ambas as décadas e que teve incremento de $850,0 \%$ das ocorrências entre os períodos. 
XVII Simpósio Brasileiro de Geografia Física Aplicada

I Congresso Nacional de Geografia Física
OS DESAFIOS DA GEOGRAFIA FÍSICA NA FRONTEIRA DO CONHECIMENTO

Instituto de Geociências - Unicamp

Campinas - SP

28 de Junho à 02 de Julho de 2017
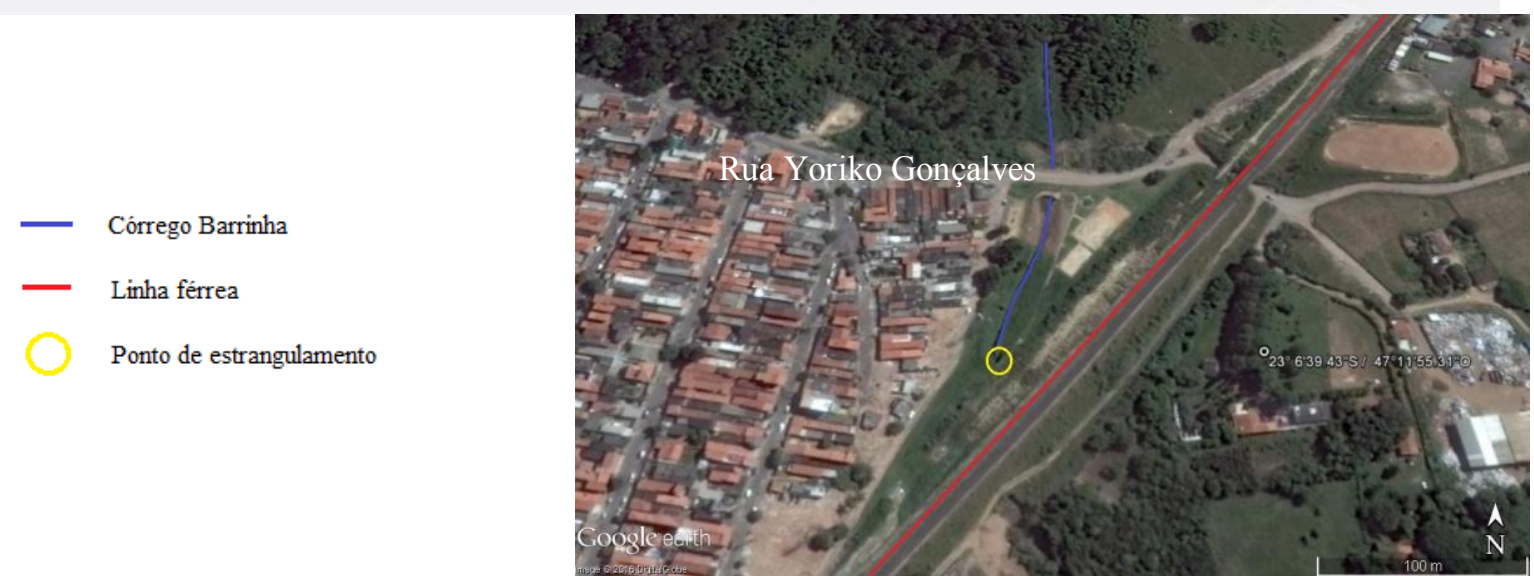

Figura 7: Jardim Oliveira Camargo, em Indaiatuba. Data: 02/07/2016. Fonte: Google Earth

O córrego passa por baixo da rua Yoriko Gonçalves e após, por baixo da linha férrea. Em dias de chuva, toda a água que precipita no bairro escoa pela rua, uma vez que o restante do bairro encontra-se em cota mais alta do que a área inundada. O córrego encontra uma barreira ao passar por baixo da linha férrea, pois a galeria ali presente, já obsoleta, não consegue escoar o volume de água (ponto de estrangulamento).

Segundo a Defesa Civil, o aumento nas ocorrências da década de 1990 para a de 2000 se deve em virtude da impermeabilização e crescimento de bairros situados em cotas mais altas, dentre deles: Jardim Belo Horizonte e Jardim Califórnia.

De acordo com o órgão, algumas moradias foram retiradas da área de inundação em 2007, porém os problemas ainda persistem, uma vez que seria necessário o alargamento da galeria que passa embaixo da linha férrea para amenizar a situação. Como a ferrovia está ativa e pertence à América Latina Logística Malha Paulista S.A., dificilmente a empresa pararia suas atividades para que a obra fosse feita, portanto, por enquanto, não há previsão de solução.

\section{Consideracões Finais}

A maioria das ocorrências de todos os municípios, para as décadas de 1990 e 2000, se deu em áreas de baixa ou muito baixa vulnerabilidade (Figura 4), resultado que destoa de grande parte das pesquisas que tratam do tema. Tal fato pode estar ligado à diminuição da desigualdade verificada em todo o Brasil na década de 2000, em virtude de três fatores: um mercado de trabalho menos desigual, a política de reajustes de benefícios previdenciários e o Programa Bolsa Família (IPEA, 2012). Tal tendência mostra que toda a população está exposta a algum tipo de risco, independente da classe social que ocupa, visto que, de maneira geral, os estratos menos vulneráveis foram bastante afetados.

Entretanto, apesar da melhora apresentada, os bairros aqui destacados (Residencial Gênesis em Campinas e ao Jardim Oliveira Camargo em Indaiatuba), não seguiram esta tendência, sendo áreas de mais alta 
vulnerabilidade, se comparadas a outros bairros dos respectivos municípios. Tal fato foi verificado em atividades de campo, em conversas com as Defesas Civis e pelo conhecimento prévio das áreas por parte das autoras. Especificamente nesses casos, tal fato corrobora com o que é dito por parte da literatura, que atenta para o fato de grupos menos favorecidos estarem mais vulneráveis a esses eventos.

Notou-se também que o município de Campinas se destacou diante dos demais por ter tido mais ocorrências no período, além de ter apresentado muitas UDHs com grande quantidade de casos. Por outro lado, Campinas mostrou ter havido melhora da década de 1990 para a de 2000, expondo que as ações da Defesa Civil estão surtindo efeito no sentido de amenizar os impactos devido a uma série de fatores, entre eles a ajuda dos moradores que vivem em áreas críticas de inundação e da infraestrutura oferecida para o trabalho dos funcionários. Como a Defesa Civil de Campinas iniciou suas atividades no início da década de 1990, pode-se atrelar o período de menor número de casos (década de 2000) àquele em que o órgão já estaria atuando de maneira mais estruturada, diferente do que ocorre nas Defesas Civis dos outros municípios, que se estruturaram mais recentemente (a maioria, no fim da década de 2000).

\section{$\underline{\text { Agradecimentos }}$}

As autoras agradecem à Fundação de Amparo à Pesquisa do Estado de São Paulo (FAPESP) pelo financiamento dado à pesquisa (Processo 2012/00883-7). Os resultados integram também o Projeto Temático FAPESP IVA (Proc. 2008/58161-1).

\section{Referências Bibliográficas}

BRAGA, T. M.; OLIVEIRA, E. L.; GIVISIEZ, G. H. Avaliação de metodologias de mensuração de risco e vulnerabilidade social a desastres naturais associados à mudança climática. São Paulo em Perspectiva, n. 1, 2006.

FERNANDES, A. C. A.; BRANDÃO, C. A.; CANO, W. A Região Metropolitana de Campinas: Análise Integrada. In: BRANDÃO, C. A.; CANO, W. (Orgs.). A Região Metropolitana de Campinas: urbanização, economia, finanças e meio ambiente. Campinas: Unicamp, 2002.

HOGAN, D. J.; CUNHA, J. M. P. da; CARMO, R. L do; OLIVEIRA, A. A. B. De. Urbanização e vulnerabilidade sócio-ambiental: o caso de Campinas. In: HOGAN, D. J.; BAENINGER, R.; CUNHA, J. M. P; CARMO, R.L. (orgs.). Migração e Ambiente nas Aglomerações Urbanas. Campinas: NEPO, UNICAMP, 2001.

IPEA - Instituto de Pesquisa Econômica Aplicada. A Década Inclusiva (2001-2011): Desigualdade, Pobreza e Políticas de Renda. n. 155, 2012.

NUNES, L.H. Mudanças climáticas, extremos atmosféricos e padrões de risco a desastres hidrometeorológicos. In: HOGAN, D. J.; MARANDOLA JR, E. (Orgs). População e Mudança Climática. Dimensões Humanas das Mudanças Ambientais Globais. Campinas: NEPO, Unicamp; Brasília: UNFPA, 2009.

PIRES, M. C. S. e SANTOS, S. M. M. Evolução da mancha urbana. In: FONSECA, R. B.; DAVANZO, A. M. Q.; NEGREIROS, R. M. C. (Orgs.). Livro Verde: desafios para a gestão da Região Metropolitana de Campinas. Campinas: UNICAMP. IE, 2002. 498p.

SEADE - Fundação Sistema Estadual de Análise de Dados. Perfil Municipal. Disponível em: http://produtos.seade.gov.br/produtos/perfil/. Acessado em setembro de 2014.

WISNER, B.; BLAIKIE, P.; CANNON, T.; DAVIS, I. At Risk: natural hazards, people's vulnerability and disaster. Nova Iorque: Routledge, 1994. 